Milina J. Kosanović

УДК

Visoka turistička škola strukovnih studija

$811.163 .41 ' 367.623$

Beograd

$811.111^{\prime} 267.623$

ДОИ

https://doi.org/10.18485/analiff.2016.28.2.14

\title{
O SEMANTICI PRIDEVA KOJI OZNAČAVAJU EMOCIJE U ENGLESKOM I SRPSKOM JEZIKU: KOGNITIVNOLINGVISTIČKA ANALIZA
}

\begin{abstract}
Pridevi kao vrsta reči tek su poslednjih decenija pobudili veće interesovanje lingvista, te se može reći da je ovo polje proučavanja još relativno neistraženo. Sa druge strane emocije su od kraja XX veka nadalje postale jedna od glavnih tema istraživanja u psihologiji, sociologiji pa i kognitivnoj lingvistici. Ovaj rad u okviru kognitivnolingvističkog teoretskog okvira govori o semantici prideva koji označavaju emocije. Pored metafore i metonimije koje predstavljaju jedan od mehanizama tvorbe ovih prideva, u radu se ukazuje i na veći broj drugih karakteristika kao što su: polisemija u smislu modifikovanja različitih tipova imenica, kolociranje sa pojedinim predlozima, značenje trenutnog ili trajnog emocionalnog stanja (ljudske osobine) i uloga atributivnosti i predikativnosti u ostvarenju ovog značenja, baš kao i glagolsko poreklo. Izneti uvidi mogu da posluže kao putokazi u daljem istraživanju kako prideva tako i emocija u okviru kognitivne lingvistike, pa i psihologije.
\end{abstract}

Ključne reči: pridevi, emocije, atributivnost, predikativnost, metafora, metonimija, kognitivna lingvistika, semantika

\section{Uvod}

Tek u poslednjim decenijama pridevima kao vrsti reči poklonjeno je više pažnje (Flanagan, 2014). U okviru kognitivne lingvistike značajna zapažanja o pridevima iznela je A. Wierzbicka $(1988: 483,486)$ koja je prideve s obzirom na njihova semantička svojstva svrstala negde na sredinu kontinuuma između imenica i glagola. Naime, dok imenice prototipično označavaju neki trajniji skup osobina, te sledstveno tome učestvuju u kategorizaciji relativno trajnih pojava, glagoli obično označavaju trenutne i promenljive karakteristike, te dakle učestvuju u kategorizaciji kratkoročnijih pojava. Pridevi kao klasa reči mogu da označe i trenutno i trajno

Elektronska adresa autora:milinak@visokaturisticka.edu.rs,milinabgd@hotmail.com 
stanje te bi se moglo reći da oni predstavljaju sredstvo kategorizacije koje bi se nalazilo negde na sredini između ova dva kraja kontinuuma. Kada govorimo o pridevima koji označavaju emocije ${ }^{1} \mathrm{u}$ engleskom i srpskom kao i u ostalim indoevropskim jezicima možemo reći da je ovakvo gledište opravdano, pa tako čak i isti pridev koji označava emocionalno stanje može posedovati kako značenje trenutne osobine tako i značenje trajnog stanja, zavisno od konteksta (na primer E happy, cheerful, S srećan, veseo) o čemu je pisala i R. Dragićević (2001: 173). Što se tiče ostalih jezika, novija tipološka proučavanja (Dixon \& Aikhenvald, 2006) pokazuju da je moguće zastupati stav da pridevi kao klasa reči postoje u svim jezicima, mada su ranije neki autori pretpostavljali da u nekim jezicima zapravo pridevi i ne postoje kao vrsta reči, pre svega zbog velike sličnosti koju u tim jezicima pokazuju bilo sa imenicama bilo sa glagolima ili sa obe ove vrste reči. S obzirom na to koliko se odmaklo u dosadašnjim istraživanjima, čini se da najispravnije stanovište jeste to da u svim jezicima postoji klasa reči koja bi se mogla nazvati pridevima, ali da to ne znači da je ta klasa uvek nezavisna od klase imenica ili glagola (Spencer, 2008: 409).

Sa druge strane, kada govorimo o proučavanju emocija, ono je još od davnina predmet kojim se bavi filozofija i retorika, a u savremeno doba emocije predstavljaju predmet proučavanja prevashodno psihologije, ali i neurologije, psihijatrije, sociologije, antropologije kao i primenjene psihologije u oblasti marketinga, edukacije itd. Interesantno je da je značenje trenutnog emocionalnog stanja i trajnih karakternih crta u psihologiji dosta dugo proučavano odvojeno, ali da će se po svemu sudeći takav pristup menjati, pri čemu upravo značenja trenutnog i trajnog stanja prideva koji iskazuje emocije predstavljaju inspiraciju za psihologe (Plutchik, 2001: 350). Naime, u današnjoj psihologiji postoji izrazito nastojanje da se povuče jasna granica između kratkotrajne emocije i raspoloženja (Scherer, 2005), a još više između osećaja (oseta), emocija i crta ličnosti, međutim, mada je distinkcija između ovih pojava svakako opravdana, isto tako je neophodno i uvažavanje određenog kontinuuma između njih (Robinson, 2008: 155). U tom smislu, kognitivnolingvističko ispitivanje značenja trenutnog ili trajnog emocionalnog stanja izraženog pridevima u jeziku može da posluži i kao osnova za plodonosan dijalog lingvista i psihologa o ovom pitanju.

1 Prilikom definisanja toga koji pridevi označavaju emocije poći ćemo od najšire definicije pojma emocije, te ćemo dakle govoriti o pridevima koji mogu da označe vrlo širok raspon emocionalnih stanja i raspoloženja, odnosno koji mogu da označe bilo kakav ,afekat"“ (Barrett, 2006: 31). 
O SEMANTICI PRIDEVA KOJI OZNAČAVAJU EMOCIJE

U ENGLESKOM I SRPSKOM JEZIKU: KOGNITIVNOLINGVISTIČKA ANALIZA

U okviru kognitivnolingvističke analize prideva koji označavaju emocije možemo se usredsrediti na više semantičkih aspekata koje se tiču ovih prideva. Neke od ovih karakteristika nisu neposredno vidljive pri posmatranju ovih leksema van konteksta. Na primer, takav je slučaj sa polisemijom ovih prideva koja im omogućava da modifikuju različite tipove imenica (osobu, ponašanje, objekat koji prouzrokuje emociju). Takođe, njihova kolokacija sa pojedinim predlozima vidljiva je tek na nivou sintakse. Za razliku od toga, glagolsko poreklo ili metafora i metonimija koje stoje u njihovoj osnovi jasno su vidljivi i na nivou lekseme. Značenje trenutnog ili trajnog emocionalnog stanja donekle je specifična odlika po stepenu transparentnosti na nivou lekseme. Naime, neki pridevi se van konteksta prototipično vezuju za trenutno stanje (E fascinated, S oduševljen), a neki za trajno stanje (E brave, S hrabar) ${ }^{2}$, no mnogi od njih mogu u kontekstu da označe upravo suprotno stanje. Ovaj rad ima zadatak da ukratko predstavi kognitivnolingvistički pristup semantici engleskih i srpskih prideva koji izražavaju emocije koje smo uočili tokom rada na svojoj doktorskoj tezi koja nosi naslov Pridevi koji označavaju emocije u engleskom i srpskom jeziku: kognitivnolingvistička analiza i koja je još u fazi izrade.

\section{Polisemija prideva koji označavaju emocije povezana sa tipom imenice koju modifikuju}

Pridevi koji označavaju emocije, kako to navodi Anna Goy (2000: 50), mogu se upotrebiti da označe tri različita tipa imenice ${ }^{3}$ :

a) osobu/subjekta osećanja (E a sad man, S tužan čovek)

b) ponašanje subjekta osećanja/ ekspresiju (E a sad expression, $\mathrm{S}$ tužan izraz lica)

c) objekat/uzrok osećanja (E a sad movie, S tužan film)

2 Hrabrost spada i u emocije, a ne samo u ljudske osobine, s obzirom da može da označi i trenutno i trajno emocionalno stanje suprotno od straha. Hrabrost je u emocije uvrstio još Aristotel, a u savremenoj literaturi Stocker (2010) hrabrost naziva jednom od „,intelektualnih emocija“ koja se oslanja na procenu da je cilj vredniji od opasnosti. Nesumljivo je postojanje jezičkih potvrda u kojima se hrabrost naziva emocijom (E emotion of courage, S emocija hrabrosti). Yang, Milliren i dr. (2010:3) objašnjavaju kako se hrabrost može smatrati vrlinom, mentalnim stanjem, stavom, emocijom, silom ili akcijom. Shvaćena kao emocija suprotna strahu, hrabrost je bliska želji, a u nekom slučajevima i ljutnji.

3 Radi ilustrativnosti, u zagradi smo naveli svoje primere na engleskom i srpskom jeziku, dok su slični primeri navedeni u originalu na engleskom i italijanskom jeziku. 
Anna Goy (2000:50) ova značenja naziva: (a) statično značenje, (b) manifestativno značenje i (c) uzročno značenje. Ipak, svi pridevi koji označavaju emocije ne poseduju iste mogućnosti polisemije po ovom pitanju. S obzirom na tip imenice koju modifikuju, pridevi se mogu podeliti na one koji poseduju (Goy, 2000: 50):

a) sva tri značenja $(\mathrm{a}, \mathrm{b}, \mathrm{c})$ (E sad, S tužan)

b) samo statično i manifestativno značenje (a, b) (E angry, S ljutit )

c) samo uzročno značenje (c) (E attractive, S privlačan)

Međutim, moramo da dodamo da je u jeziku moguće da neki pridev koji označava emociju poseduje isključivo manifestativno značenje (b). Takav je slučaj sa nekim srpskim pridevima koji izražavaju tipično ponašanje subjekta emocije zasnivajući se na metonimijskom prenosu. Kao primer za ovo može se navesti pridev S plačan u sintagmi S plačni glas koji označava emocionalno stanje tuge ili straha i pridev S ispitivački (pogled) koji označava radoznalost ili nepoverenje (sumnju, zbunjenost). Postoje i pridevi sa isključivo manifestativnim značenjem koji preko metaforičnog (metaftonimičnog) prenosa izražavaju neku emociju kao što je to slučaj sa pridevom $\mathrm{S}$ žučan u sintagmi $\mathrm{S}$ žučna rasprava, koji izražava bes ili netrpeljivost. U engleskom jeziku neki pridevi takođe imaju isključivo manifestativno značenje kao, recimo, pridev E acrimonious (dispute, negotiations) koji po značenju odgovara srpskom pridevu S žučan.

Koliko nam je poznato, pridevi koji označavaju emocije u engleskom i srpskom jeziku do sada nisu bili podrobno ispitivani na ovaj način, te bi bilo vrlo interesantno klasifikovati ih prema predloženim kriterijumima i utvrditi da li postoje određene pravilnosti u pogledu ispoljavanja ovakve polisemičnosti.

\section{Mogućnost kolokacije prideva koji označavaju emocije sa predlozima}

Konceptualizacija emocija umnogome počiva na uočavanju određenog kognitivnog scenarija koji stoji u njihovoj osnovi (Lakoff, 1987: 380; Wierzbicka, 1999; Dragićević, 2010). Možemo uočiti da se u okviru kognitivnog scenarija emocija vrlo često uspostavlja odnos između subjekta emocije i nekog objekta. Pri tom ovaj odnos može počivati na dejstvu spoljašnjeg objekta na subjekat, ili obrnuto - na dejstvu subjekta na 
O SEMANTICI PRIDEVA KOJI OZNAČAVAJU EMOCIJE

U ENGLESKOM I SRPSKOM JEZIKU: KOGNITIVNOLINGVISTIČKA ANALIZA

objekat. Tako možemo reći da je neko "zainteresovan za knjigu” pošto ga je knjiga zainteresovala i na taj način ćemo iskazati dejstvo objekta (knjige) na subjekta (čoveka). Međutim, možemo reći i da je neko "brižan prema drugima" pošto za njih brine, što znači da subjekat emocije saosećanja deluje na druge ljude (objekat). U engleskom i srpskom jeziku ponekad se razlikuje izbor predloga koji izražava jedno od ova dva značenja, te se tako postižu i različite iznijansiranosti značenja (E interested in, angry with, $\mathrm{S}$ zainteresovan za, ljut na). Postavlja se pitanje u kojoj meri je moguće na semantičkom nivou izjednačiti prevodne ekvivalente, te da li se, recimo, ljutnja konceptualizuje na isti način u engleskom i srpskom jeziku ukoliko postoje značajne razlike u predloškim kolokacijama prideva koji izražavaju ljutnju. U srpskom jeziku često nailazimo i na slučaj da padeški oblik imenice ostvaruje kolokaciju sa pridevom, dok se u engleskom isto značenje postiže predlogom (E scared of, $\mathrm{S}$ zastrašen (nečim)). S obzirom na to da se jedan broj kognitivnih lingvista već dosta bavio predlozima i padežima u engleskom, srpskom ili slovenskim jezicima kao na primer L. Janda (2015), K. Rasulić (2004) i D. Klikovac (2006), dok su se neki lingvisti bavili prevodnim ekvivalentima pojedinih engleskih predloga u srpskom jeziku (J. Biljetina, 2015), moguće je nadovezati se na ova istraživanja $u$ daljem proučavanju konceptualizacije emocija. Recimo, neki pridevi za označavanje emocija koji iza sebe imaju predlog E over kao što je to E triumphant over izražavaju ideju kontrole o kojoj je pisala K. Rasulić (2004:258), a neki srpski pridevi koji iza sebe zahtevaju genitiv, kao na primer S željan nekoga/nečega, mogu se valjano objasniti uz pomoć dijagrama koji slikovito prikazuje značenje genitiva kako to predlaže L. Janda (2000: 17). U našem istraživanju imali smo prilike da samo površno istražimo ovu temu mada je ona svakako logična dopuna proučavanjima metafore i metonimije koja dominiraju u kognitivnoj lingvistici i kojima se i sami najviše bavimo.

\section{Metafora i metonimija kao mehanizmi nastajanja značenja prideva koji označavaju emocije}

Izrazito veliki broj prideva koji označavaju emocije u svojoj osnovi sadrži metaforički ili metonimijski prenos. Taj prenos može se pratiti i uz osvrt na kognitivni scenario emocije. Svaka emocija poseduje svoj kogni- 
tivni scenario koji predstavlja prototipičan model celokupnog doživljavanja emocije i saznanja o njoj. Taj model obuhvata više elemenata:

1. prototipični stimulus, odnosno uzrok emocionalnog odgovora (na primer uočavanje i procena neprijatelja u kognitivnom scenariju straha)

2. psihološko-fiziološke reakcije (na primer smanjivanje telesne temperature i drhtanje u slučaju straha)

3. tipično ponašanje (na primer sakrivanje, bežanje ili napad u slučaju straha)

Elementi kognitivnog scenarija različitih emocija mogu biti u jeziku izraženi putem metafore ili metonimije. Gotovo po pravilu ovde se može zapaziti sadejstvo obe vrste prenosa (Barcelona, 2003). Na primer, jedna vrsta tipične reakcije uplašenog čoveka jeste nepomičnost ili zaustavljanje. Ukoliko se ova nepomičnost uplašenog čoveka uporedi sa nepomičnošću kipa, sadejstvo metafore i metonimije dovešće do stvaranja srpskog prideva S ukipljen, koji pored straha može da označi i iznenađenje i divljenje. U engleskom jeziku pridev E panic-stricken takođe u sebi sadrži metaforu u kojoj subjekat emocije figurativno doživljava udarac od same emocije shvaćene kao entiteta, no u osnovi ovog prideva primećujemo i metonimiju pošto se nepomičnost izazvana strahom (metonimija) poredi sa efektom udarca (metafora). Naravno, neki od prideva koji označavaju emocije zasnovani su isključivo na metonimiji (E smiling, S raspevan). Iako mnogi pridevi koji označavaju emocije svojim značenjem ukazuju na subjektivan osećaj (E cool-headed, S hladnokrvan ) ili ponašanje subjekta (E sunny, S lepršav), jedan deo ovih prideva ukazuje i na prvi element kognitivnog scenarija, dakle na uzrok osećanja. Ovi pridevi su često glagolskog porekla i potiču od prošlog participa ili glagolskog prideva trpnog (E attracted, fed up, S privučen, zasićen), mada to nije uvek pravilo (S presit). Test koji bi pokazivao na koji deo kognitivnog scenarija se odnosi neki pridev može da uključi transformacije rečenica koje bi pokazale da li se radi o ekspresiji ili o uzroku emocije. Na primer, možemo reći: „Zbog toga što oseća radost, on je lepršav. Zbog toga što oseća strah, on je ukipljen.“ Međutim ne možemo reći: „Zbog toga što oseća privlačnost, on je privučen. Zbog toga što oseća dosadu, on je presit.“" Bilo bi logičnije reći upravo obrnuto: „On je privučen (nečim) i zbog toga oseća privlačnost. On je presit (nečega) i zbog toga mu je dosadno“.

$\mathrm{U}$ okviru ispitivanja metafore i metonimije sadržane u pridevima koji označavaju emocije ponekad je neophodno osvrnuti se i na dijahronijski razvoj nekih od njih. U nekim slučajevima, pogotovu kada govori- 
O SEMANTICI PRIDEVA KOJI OZNAČAVAJU EMOCIJE

U ENGLESKOM I SRPSKOM JEZIKU: KOGNITIVNOLINGVISTIČKA ANALIZA

mo o pozajmljenicama, na nivou sinhronije nije moguće uočiti postojanje pojmovne metafore, no ona je u izvornom jeziku bila očigledna. Tako je na primer engleski pridev E contrite, u značenju „posramljen, kriv“, nastao od latinskog glagola conterere koji znači „samleti,“ što ukazuje na konceptualizaciju krivice kao nadmoćnog protivnika ili snažne sile koja melje subjekta emocije. Međutim, kod nekih pozajmljenica ta metafora može biti transparentnija. Recimo, pridev E depressed nastao je od latinskog glagola depressare u značenju ,pritisnuti nadole“ ali je ovo značenje prilično prozirno zbog toga što glagol E to depress i danas označava potonuće ili pritiskanje, dok je glagol E to press poptpuno uobičajen glagol koji označava pritisak u savremenom engleskom jeziku. U srpskom jeziku, međutim, metafora u osnovi prideva $\mathrm{S}$ depresivan nije tako prozirna jer se glagol S presovati ne upotrebljava svakodnevno u značenju pritiska, niti se jasno dovodi u vezu sa pridevom S depresivan. Ponekad, naravno, možemo uočiti neprozirnost ili poluprozirnost metafora i metonimija i u osnovi prideva domaćeg porekla. Na primer, pridev S goropadan koji označava bes ili ljutnju, u sebi sadrži poluprozirnu metaforu i metonimiju. Današnjim govornicima srpskog jezika jasno je da ovaj pridev u svojoj osnovi sadrži ideju pada, ali teško da mogu sa sigurnošću zaključiti da prvi deo složenice potiče od glagola $\mathrm{S}$ goreti ili pak od imenice $\mathrm{S}$ gora u značenju ,muka“, a da je cela složenica prvobitno označavala bolest epilepsiju (Skok, 1971: 591). Pridev S goropdan dakle sadrži metaforu LJUTNJA JE BOLEST, koja je neprozirna u današnjem jeziku, dok je metonimija u kojoj se ljutnja povezuje sa padanjem gotovo potpuno prozirna. U engleskom jeziku pridev E cross u značenju „ljut, namrgođen, neraspoložen“" u sebi sadrži gotovo neprozirnu metaforu u kojoj se ljutit čovek poredi sa nezadovoljnim mornarom na brodu preko koga vetar duva u nepovoljnom pravcu. Iako je ideja suprotstavljanja sadržana i danas u rečima poput E cross, across, te je u tom smislu jasno da se ljutnja dovodi u vezu sa nepovoljnim okolnostima koje idu nasuprot nečijim željama, ipak je celokupna metafora koja postoji u osnovi ovog prideva nerazumljiva bez konsultovanja rečnika ${ }^{4}$. S obzirom na to da su metafora i metonimija veoma često prisutne u osnovi prideva koji označavaju emocije, neophodno je pristupiti njihovoj temeljnoj analizi bar na nivou sinhronije, što je jedan od predmeta našeg trenutnog istraživanja.

4 http://www.oxforddictionaries.com/definition/english/cross 


\section{Povezanost predikativne $i$ atributivne upotrebe sa značenjem trajnosti emocionalnog stanja}

Kao što smo već pomenuli veliki broj prideva koji označavaju emocije mogu imati i značenje trenutnog i značenje trajnog emocionalnog stanja (ljudske osobine), što je komentarisala i Wierzbicka (1988: 483, 486). Ona je uočila da neki jezici, kao na primer ruski, imaju različite oblike istog prideva kada se ovaj koristi atributivno ili predikativno ${ }^{5}$, kao i da se atributivna upotreba u principu vezuje za značenje trajnog stanja, a predikativna upotreba za značenje trenutnog stanja. Prema tumačenju Wierzbicke, imenica kao vrsta reči označava trajniji skup osobina, te se značenje trajnosti koja postoji pri atributivnoj upotrebi, dakle, može tumačiti kao vezivanje značenja prideva za imenicu kao oznaku koja u sebi sadrži trajnost. Sa druge strane, Wierzbicka dovodi u vezu prideve i glagole kao reči koje označavaju manje trajne kategorije (vremenski ograničene radnje), pa u skladu sa tim možemo zaključiti da su u predikativnoj upotrebi pridevi snažnije povezani sa kopulom, tj. glagolom koji u sebi sadrži značenje promenljivosti i temporalnosti (Wierzbicka, 1988: 486). Naravno, Wierzbicka ovde govori o protipičnoj upotrebi, dopuštajući varijacije i izuzetke.

Razmatrajući ovo pitanje, u našem istraživanju došli smo do zaključka da nedostatak šireg konteksta utiče na ostvarivanje značenja trajnosti $\mathrm{u}$ atributivnoj upotrebi i trenutnog stanja u predikativnoj upotrebi, ali da atributivnost i predikativnost nisu same po sebi od odlučujuće važnosti za ovakvu distinkciju. Na primer, ako kažemo: "Peter is a calm boy; Peter is a relaxed boy “ ili „Petar je miran dečak; Petar je opušten dečak“ očigledno je da mislimo na trajno stanje, jer se pridev vezuje za imenicu E boy S dečak kao nosioce značenja trajnih kategorija. U ovakvim konstrukcijama gotovo da je isključena mogućnost značenja trenutnog stanja. Za razliku od toga kada kažemo: „Peter is calm; Peter is relaxed“ ili „, Petar je miran; Petar je opušten" to može da označi trenutno stanje, ali ni značenje trajnog stanja nije uopšte isključeno. Međutim, iako u ograničenom kontekstu atribucija i predikacija mogu da imaju značajan uticaj na postizanje značenje trenutnog ili trajnog stanja (osobine), primeri iz korpusa pokazuju da je ova povezanost samo prototipična, ali ne i obavezna.

Tako, recimo, nailazimo na primere "She saw a calm man walk out of the tunnel“" ili „U jednom trenutku jedan miran čovek počne da se vese-

5 I u srpskom jeziku postoje različiti oblici za određeni i neodređeni pridevski vid. 
O SEMANTICI PRIDEVA KOJI OZNAČAVAJU EMOCIJE

U ENGLESKOM I SRPSKOM JEZIKU: KOGNITIVNOLINGVISTIČKA ANALIZA

li, “ u kojima atributivna upotreba ne implicira trajno, već trenutno stanje. Ovde primećujemo da tek kopulativna konstrukcija u kombinaciji sa atributivnom upotrebom (He is a calm man. On je miran čovek.) uslovljava značenje trajnog stanja, dok sama atributivnost nije faktor od presudnog značaja. Sa druge strane, predikativna upotreba ne isključuje značenje trajne osobine, mada primeri iz korpusa upućuju na to da je uobičajeno da se tada spomenu dva prideva sa značenjem crte ličnosti u naporednoj konstrukciji, kao u primerima koji slede:

His father was calm and gentle, traits that his son later praised more than emulated.

http://www.stevejobsthebiography.com/extras.html

Bio je miran i povučen, drugovao je sa šumom...

Božidar Prešev, Čuvarpriča i njegovo blago

Možemo zaključiti da atributivna i predikativna upotreba engleskih i srpskih prideva prototipično ima uticaja na značenje trenutnog stanja ili trajne osobine samo u situaciji suženog konteksta, ali da u širem kontekstu ova značenja ne moraju da budu povezana sa jednom od ove dve upotrebe. Međutim, moguće je da postoji izvesna veza između prelaznosti glagola od kojih su nastali pridevi za izražavanje emocija i značenja trenutnog stanja, što smo detaljnije ispitali u toku svog istraživanja.

\section{Glagolsko poreklo i značenje trenutnog ili trajnog emocionalnog stanja}

U engleskom i srpskom jeziku iznenađujuće veliki broj prideva koji označavaju emocionalna stanja potiče od prošlog participa odnosno glagolskog prideva trpnog kao na primer E surprised, delighted, scared ili S iznenađen, oduševljen, uplašen. Najveći broj tih prideva nastao je od glagola koji mogu biti i tranzitivni i refleksivni. U srpskom jeziku ovu pojavu lakše je pratiti zbog karakteristične rečce ,se“ koja se javlja u okviru infinitiva glagola, dok u engleskom jeziku moguća, ali neobavezna upotreba povratne zamenice, po pravilu nije navedena u rečnicima, već se može videti tek iz primera iz korpusa. Dakle, pridevi poput para E relaxed, S opušten 
mogli su nastati od glagola $E$ to relax, S opustiti ili od glagola E to relax oneself, S opustiti se. S obzirom na to da se opuštenost konceptualizuje kao stanje koje može biti i posledica delovanja objekta, ali i posledica delovanja subjekta na samog sebe, jednostavno je zaključiti da trajanje ovog dejstva može, pre svega zbog mogućnosti učešća subjektove volje, da bude dugotrajno i da se ne vezuje samo za jednu konkretnu sitaciju u kojoj objekat deluje na subjekat. Tako, „opušten čovek“ jeste onaj čovek koji ume i hoće da se opusti, a ne prototipično čovek koji je stalno pod dejstvom objekta koji ga opušta (muzika, lepe reči itd.). Na osnovu ovog uvida moguće je postaviti hipotezu da će oni prideva koji su nastali od isključivo prelaznih glagola posedovati samo značenje trenutnog stanja, pošto takvi glagoli ukazuju na vremenski ograničeno dejstvo objekta na subjekat.

Ovu hipotezu pokušali smo da proverimo na materijalu oba jezika tokom istraživanja u okviru naše doktorske teze. U toku istraživanja obradili smo ukupno 732 engleskih i 418 srpskih prideva koji označavaju emocije, i to onih koji bliže određuju subjekta emocije. Među engleskim pridevima 30\% vodi poreklo od prošlog participa, a $8 \%$ vodi poreklo od sadašnjeg participa, što ukupno daje postotak od 38\% . Među srpskim pridevima 38\%, vodi poreklo od glagolskog prideva trpnog, ali nijedan ne vodi poreklo od glagolskog prideva sadašnjeg. Mimo ovoga, pojedini pridevi u oba jezika povezani su sa glagolima, ali ne na direktan način, već samo preko korena (E figety, shaky ili S lepršav, odvažan, popustljiv).

Nalazi do kojih smo došli prilikom istraživanja govore u prilog hipotezi koju smo izneli da pridevi nastali od isključivo tranzitivnih glagola odslikavaju samo trenutno stanje, s obzirom na to da odslikavaju stanje prouzrokovano konkretnim objektom. Međutim, naša analiza je pokazala da je broj prideva koji su nastali od glagola koji su isključivo tranzitivni u oba jezika veoma mali u odnosu na celokupan broj prideva nastalih od glagola. Na primer, takvi su pridevi E attracted ${ }^{6}$, seduced, S privučen, primamljen koji označavaju emociju privlačnosti, pridevi E tickled, S zagolican koji izražavaju interesovanje, zatim pridevi E dazzled, hypnotized, spellbound, S zaslepljen, hipnotisan, omađijan koji izražavaju

6 Pridev E attracted nastao je metaforičnim prenosom. Osnovno značenje glagola E to attract je fizičko privlačenje kao na primer u rečenici: Magnets attract iron fillings. Čak i sama reč vodi poreklo od latinske reči ad+trahere - to pull, to draw http://www.merriam-webster.com/dictionary/attract

Srpski pridev S privučen potpuno prozirno izražava istu pojmovnu metaforu. 
O SEMANTICI PRIDEVA KOJI OZNAČAVAJU EMOCIJE

U ENGLESKOM I SRPSKOM JEZIKU: KOGNITIVNOLINGVISTIČKA ANALIZA

divljenje. Takođe takvi su i pridevi E saddened, dejected, S utučen, ojađen koji iskazuju tugu i razočaranje ili pridevi E daunted, S zastrašen, ustrašen koji izražavaju strah. Navedeni pridevi koji označavaju prijatne emocije rezultat su metaforičnog prenosa, a navedeni pridevi koji označavaju neprijatne emocije ne sadrže u sebi eksplicitnu metaforu, već samo ideju dejstva objekta na subjekat. Ipak, može se primetiti da je čak i sama ideja dejstva objekta na čoveka prilikom doživljavanja emocija u određenoj meri metaforična sama po sebi, pošto na primer objekat koji nas je zastrašio ne mora nužno namerno da nas straši, odnosno da bukvalno deluje na nas. Međutim, najznačajnija otežavajuća okolnost pri donošenju definitivnih zaključaka koji se tiču engleskih prideva koji označavaju emocije, a nastali su od tranzitivnih glagola, sastoji se u tome što u engleskim rečnicima nije uobičajeno da uz tranzitivni glagol bude navedena i refleksivna zamenica koja ih eventualno može pratiti, što znači da je neophodno konsultovanje korpusa za svaki pojedini glagol.

\section{Zaključak}

Pridevi koji označavaju emocije u engleskom i srpskom jeziku imaju veliki broj semantičkih karakteristika koji zaslužuju pažnju istraživača. Imajući u vidu to da je više od trećine ovih prideva glagolskog porekla, svakako bi bilo zanimljivo podrobnije istražiti tipove glagola od kojih su ovi pridevi nastali. Sinhronijsko i dijahronijsko istraživanje metafora i metonimija koje stoje u osnovi ovih prideva verovatno je jedno od najinspirativnijih polja istraživanja u kognitivnoj lingvistici kojim se i sami bavimo. Međutim, smatramo da i polisemija koju ovi pridevi ispoljavaju u pogledu tipa imenice sa kojom kolociraju predstavlja jedan od važnih pravaca istraživanja, baš kao i predlozi koji ih prate. Smatramo da ovakvo istraživanje ne bi doprinelo samo boljem razumevanju prideva koji označavaju emocije u lingvistici, već da bi bolje osvetlilo i konceptualizaciju emocija uopšte, što može biti inspirativno i za psihologe ili psihoterapeute (Hartley, 2012). Čini se da bi u budućnosti značajnija saradnja psihologa i kognitivnih lingvista mogla da olakša istraživanje stručnjacima iz obe oblasti, pružajući nove uvide u mnoge zanimljive teme koje se podjednako tiču i emocija i jezika. 


\section{Literatura:}

Barcelona, A. (2003). On the plausibility of claiming a metonymic motivation for conceptual metaphor. Metaphor and Metonymy at the Crossroads (A. Barcelona ed.) (pp. 31-58). Berlin, New York: Mouton de Gruyter

Biljetina, J. (2015). Serbian equivalents of the English preposition of: a contrastive corpus analysis. Zbornik za jezike i književnost Filozofskog fakulteta u Novom Sadu, godina 5, br. 5, 81-91

Dixon, R.M.W. Aikhenvald, A. Y. (2006). Adjective Classes: A Cross-linguistic Typology. Oxford: Oxford University Press

Dragićević, R. (2010). Verbalne asocijacije kroz srpski jezik i kulturu. Beograd: Društvo za srpski jezik i književnost Srbije

Flanagan, P. (2014). A Cross-Linguistic Investigation of the Order of Attributive Adjectives. Doctoral thesis. Edge Hill University, Ormskirk

Goy, A. (2000). Lexical Semantics of Emotional Adjectives. MIT Working Papers in Linguistics 37, 49-61

Hartley, T. (2012). Cutting Edge Metaphors. Journal of the Association of Surgeons of Great Britain and Ireland, No.37, 26-29

Janda, L. (2000). Cognitive Linguistics. SLINGK2K Workshop

https://slaviccenters.duke.edu/uploads/media_items/8janda.original.pdf

Janda, L. (2015). Cognitive Linguistics in 2015. Cognitive Semantics 1, $131-154$

Plutchik, R. (2001). The Nature of Emotions. American Scientist, Vol.89, 344-350

Rasulić, K. (2004). Jezik i prostorno iskustvo. Beograd: Filološki fakultet

Robinson, D.L. (2008). Brain Function, Emotional Experience and Personality. Netherlands Journal of Psychology, 64, 152-167

Scherer, K.R. (2005). What are emotions? And how they can be measured? Social Science Information, 44(4), 693-727

Skok, P. (1971). Etimologijski rečnik hrvatskoga ili srpskoga jezika. Zagreb: Jugoslavenska akademija znanosti i umetnosti

Spencer, A. (2008) Adjective Classes: A Cross-linguistic Typology (review). Language, Volume 84, Number 2, Linguistic Society of America, 407-409

Stocker, M. (2010) Intelectual and other non-standard emotions . The Ox- 
ГЛАГОЛСКИ ВИД У СРПСКОМ И САВРЕМЕНОМ ГРЧКОМ: ИЗМЕЪУ СЕМАНТИКЕ И ПРАГМАТИКЕ

ford Handbook of Philosophy of Emotions (ed. Peter Goldie) (pp. 401-425). New York: Oxford University Press

Wierzbicka, A. (1988) The Semantics of Grammar. Amsterdam, Philadelphia: John Benjamins Publishing Company

Wierzbicka, A. (1999) Emotional universals. In: Language Design 2, 2369

Yang, J., Milliren A., Blagen, M. (2010) The Psychology of Courage- An Adlerian Handbookfor Healthy Socila Living. New York, Routledge

\section{Internet izvori:}

www.merriam-webster.com

www.oxforddictionaries.com

Milina Kosanović

\section{Summary}

\section{THE SEMANTICS OF ADJECTIVES DENOTING EMOTIONS IN ENGLISH AND SERBIAN - COGNITIVELINGUISTIC APPROACH}

Adjectives have aroused the major interest of linguists only in the recent decades, leaving this field still comparatively underexplored. On the other hand, since the end of the 20th century, emotions have taken centre stage in psychology, sociology as well as in cognitive linguistics. This paper explores the cognitivelinguistic approach to the semantics of adjectives denoting emotions in English and Serbian. Along with metaphor and metonymy which motivate a number of these adjectives, the paper outlines a few additional aspects such as polysemy related to the type of the noun modified, collocations with particular prepositions and the role of attibutive and predicative use of the adjectives or their deverbal origin in denotation of temporary or permanent emotional states. The conclusions of the paper may represent an incentive for further exploration of both adjectives and emotions in cognitive linguistics or psychology.

Key words: adjectives, emotions, attributive use, predicative use, metaphor, metonymy, cognitive linguistics, semantics 